\title{
SULFATION PATHWAYS
}

\section{Expression of SULT2A1, SULT2B1 and HSD3B1 in the porcine testis and epididymis}

\author{
B Zimmer, L Tenbusch, M C Klymiuk, Y Dezhkam and G Schuler \\ Veterinary Clinic for Obstetrics, Gynecology and Andrology, Justus-Liebig-University, Giessen, Germany \\ Correspondence should be addressed to G Schuler: gerhard.schuler@vetmed.uni-giessen.de \\ This paper is part of a thematic section on Sulfation Pathways. The guest editors for this section were Jonathan Wolf Mueller and Paul Foster.
}

\begin{abstract}
In the porcine testis, in addition to estrogen sulfates, the formation of numerous sulfonated neutral hydroxysteroids has been observed. However, their functions and the underlying synthetic pathways are still widely unclear. To obtain further information on their formation in postpubertal boars, the expression of sulfotransferases considered relevant for neutral hydroxysteroids (SULT2A1, SULT2B1) was investigated in the testis and defined segments of the epididymis applying real-time RT-qPCR, Western blot and immunohistochemistry (IHC). Sulfotransferase activities were assessed in tissue homogenates or cytosolic preparations applying dehydroepiandrosterone and pregnenolone as substrates. A high SULT2A1 expression was confirmed in the testis and localized in Leydig cells by IHC. In the epididymis, SULT2A1 expression was virtually confined to the body. SULT2B1 expression was absent or low in the testis but increased significantly along the epididymis. Immunohistochemical observations indicate that both enzymes are secreted into the ductal lumen via an apocrine mechanism. The results from the characterization of expression patterns and activity measurements suggest that SULT2A1 is the prevailing enzyme for the sulfonation of hydroxysteroids in the testis, whereas SULT2B1 may catalyze the formation of sterol sulfates in the epididymis. In order to obtain information on the overall steroidogenic capacity of the porcine epididymis, the expression of important steroidogenic enzymes (CYP11A1, CYP17A1, CYP19, HSD3B1, $H S D 17 B 3, S R D 5 A 2)$ was monitored in the defined epididymal segments applying real-time RT-qPCR. Surprisingly, in addition to a high expression of SRD5A2 in the epididymal head, a substantial expression of HSD3B1 was detected, which increased along the organ.
\end{abstract} Key Words

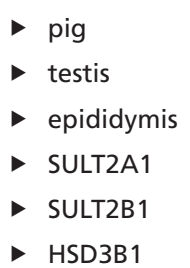

Journal of Molecular Endocrinology (2018) 61, M41-M55

\section{Introduction}

Historically, sulfonation of steroids has been mainly regarded as an important pathway to limit their effects and to facilitate elimination, rendering to steroid sulfates a role of inactive metabolic end products. However, more recently, the concept of sulfonated steroids has become much more complex, and their role as substrates for the local intra-tissue production of bioactive steroids and functions distinct from unconjugated counterparts have attracted increasing attention (for review see Dawson 2012, Mueller et al. 2015). An intriguing feature of boars among 
the males of domestic mammalian animal species is their unusually broad spectrum of sulfonated steroids, which partly circulate at remarkably high concentrations (Baulieu et al. 1967, Claus \& Hoffmann 1980, Schwarzenberger et al. 1993, Raeside et al. 2006, Schuler et al. 2014, 2018a). For example, in our previous study (Schuler et al. 2018a), highest concentrations found in the systemic circulation for sulfonated epiandrosterone, 5 -androstene-3 $\beta, 17 \beta$ diol, epitestosterone, dehydroepiandrosterone and estrone were 236, 131, 78, 63 and $43 \mathrm{ng} / \mathrm{mL}$, respectively. However, concentrations varied significantly between individual animals and exhibited considerable diurnal fluctuations. For the majority of sulfonated steroids, data from measurements in testicular vein (Baulieu et al. 1967, Gower et al. 1970, Raeside \& Howells 1971, Setchell et al. 1983, Raeside et al. 2006, Schuler et al. 2014, 2018a) or in lymph fluid of the spermatic cord (Setchell et al. 1983) clearly point to the testicular-epididymal compartment as their predominant source. Many of the sulfonated steroids occurring in boars have been measured at high concentrations in testicular tissue (Ruokonen \& Vihko 1974). This observation provides clear evidence for the testis as the predominant site where sulfonation takes place and observations from in vitro experiments using purified Leydig cells indicate that they are the main producers of sulfonated estrogens and several sulfonated C19-steroids (Raeside \& Renaud 1983, Orava et al. 1985, Raeside et al. 1992, Sinclair et al. 2005). The biological role of steroid sulfonation in the porcine testis is widely unclear, and it is still elusive why the porcine testis inactivates bioactive steroids (estrogens, steroidal pheromones) immediately after their production in Leydig cells and why it removes important intermediates of steroidogenesis such as pregnenolone (P5), dehydroepiandrosterone (DHEA) or 5 -androstene-3 $\beta, 17 \beta-$ diol from the pool of unconjugated steroids.

Sulfonated steroids arise from the activities of several members of the large supergene family of cytosolic sulfotransferases (SULTs), which catalyze the sulfonation of small endogenous molecules and xenobiotics. In humans, SULTs $2 \mathrm{~A} 1$ and $2 \mathrm{~B} 1$ have been identified as the relevant sulfotransferases for neutral hydroxysteroids. SULT2A1 exhibits a broad substrate spectrum. In addition to its prototypical substrate DHEA and other $3 \beta$-hydroxysteroids, it is also capable of sulfonating $3 \alpha$-hydroxysteroids, estrogens and xenobiotics. For human SULT2B1, P5 (isoform 2B1a) and cholesterol (isoform 2B1b) are regarded as preferential steroidal substrates (Falany et al. 1995, Strott 2002, Gamage et al. 2006, Dawson 2012, Pasqualini 2009, Falany \& Rohn-Glowacki 2013, Mueller et al. 2015). Information on the substrate specificities and organization of SULTs $2 \mathrm{~A} 1$ and $2 \mathrm{~B} 1$ in other species is still sparse, but observations made so far point to considerable species differences (Kohjitani et al. 2006, Falany \& Rohn-Glowacki 2013, Mueller et al. 2015). Despite some information on steroid sulfonation in the porcine testis from studies on enzyme activities in testicular tissue (Cooke et al. 1983, Hobkirk et al. 1989, Sinclair et al. 2006) and the formation of sulfonated steroids in Leydig cell culture (Raeside \& Renaud 1983, Orava et al. 1985, Raeside et al. 1992, Sinclair et al. 2005), many questions are still open concerning the involvement of individual SULTs during steroid sulfonation in the porcine testis. Moreover, in previous studies a considerable estrogen sulfotransferase activity was detected in the porcine epididymis (Hoffmann et al. 2010, Zdunczyk et al. 2012, Schuler et al. 2018b), pointing to this organ as another relevant site of steroid sulfonation in boars. Thus, in order to obtain new insights into the sulfonation of neutral hydroxysteroids in the porcine testicular-epididymal compartment, the major aims of this study were to characterize the expression of SULTS $2 A 1$ and $2 B 1$ in the porcine testis and defined segments of the epididymis and to assess the sulfonation of DHEA and P5 in corresponding tissue samples. Moreover, to obtain a more holistic view on steroid production and metabolism in the porcine testicular-epididymal compartment, the defined segments of the epididymis were also screened for the expression of steroidogenic enzymes catalyzing important conversions of free steroids.

\section{Materials and methods}

\section{Collection and preparation of tissue samples}

All animal experiments were in accordance with the relevant regulations (permit No. V54-19c-20-15(I) Gi 18/14-No. 32/2010; Regierungspraesidium Giessen). Tissue samples were collected from a total number of ten postpubertal crossbreed boars (nine German Landrace $\times$ Pietrain, one Large White) aged between 10 and 16 months. The testes with epididymis and spermatic cord were removed under general anesthesia $(2 \mathrm{mg} / \mathrm{kg}$ BW azaperone, Stresnil - Janssen Animal Health, Neuss and $20 \mathrm{mg} / \mathrm{kg}$ BW ketamine, Ursotamin $100 \mathrm{mg} / \mathrm{kg}-$ Serumwerk Bernburg AG, Bernburg) and transported on ice to the laboratory within $5 \mathrm{~min}$. For Western blot (WB) analysis and for measurements of relative gene expression (RGE) and enzyme activities, tissue samples were prepared from the following localizations (Fig. 1): upper and lower half of the testis (TE1, TE2), proximal and distal part of epididymal head (EH1, EH2), four 


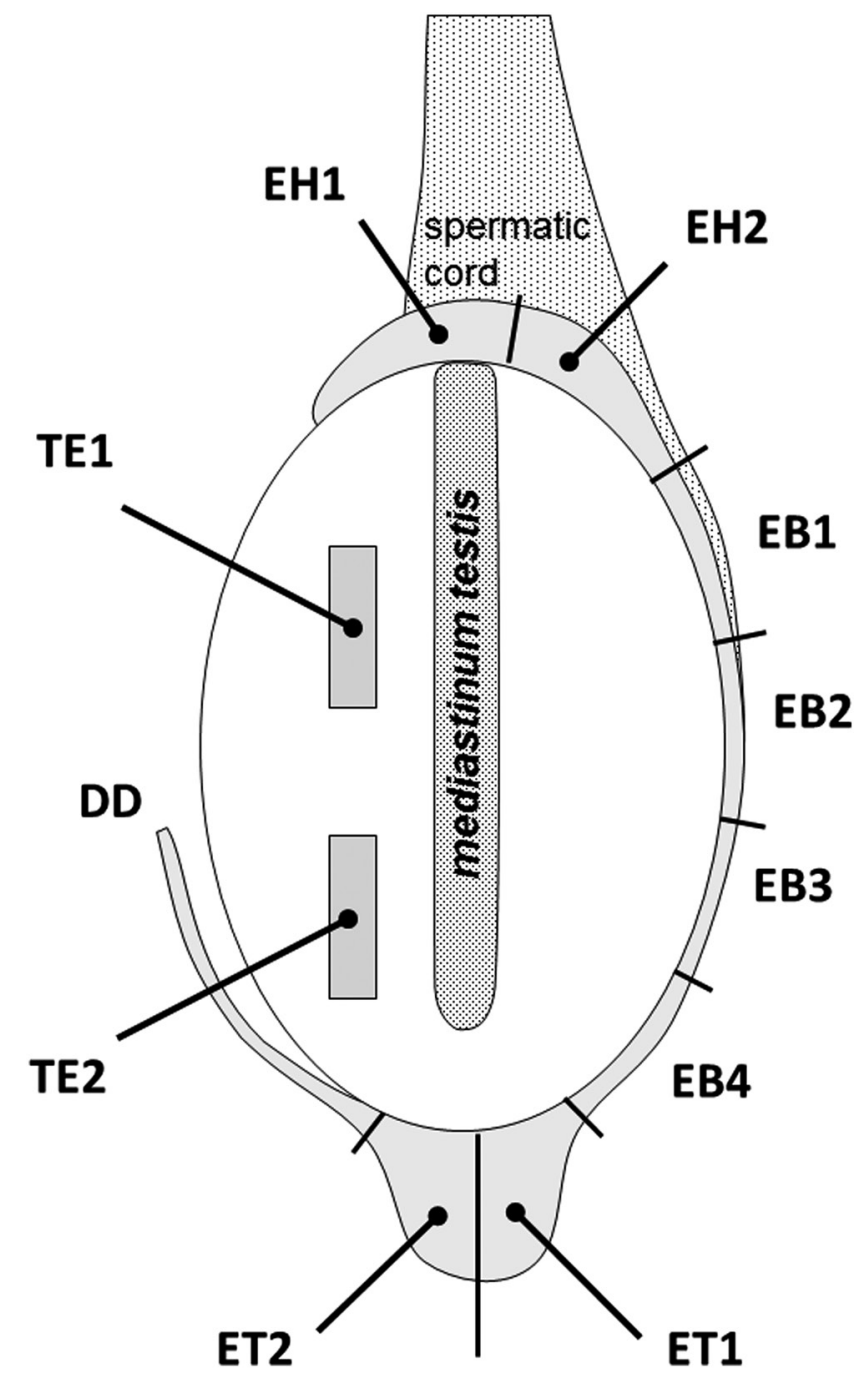

Figure 1

Localizations of tissue sampling. DD, deferent duct; EB1-4, segments of epididymal body, from proximal to distal; EH1, EH2, proximal/distal segment of epididymal head; ET1, ET2, proximal/distal segment of epididymal tail; TE1, TE2: testicular parenchyma in the upper/lower half of testis.

segments of the epididymal body (EB1-4, from proximal to distal), proximal and distal part of epididymal tail (ET1, ET2) and the deferent duct (DD); they were stored at $-80^{\circ} \mathrm{C}$ until further analysis. Correspondingly, for immunohistochemistry (IHC) tissue samples collected from the same localizations were fixed for $20-24 \mathrm{~h}$ in $10 \%$ neutral phosphate-buffered formalin.

\section{Measurement of relative target gene mRNA levels by real-time RT-qPCR}

Pieces of frozen tissue samples $\left(-80^{\circ} \mathrm{C}\right)$ were pulverized in a pre-chilled mortar with a pestle under liquid nitrogen. Total RNA was isolated from $100 \mathrm{mg}$ of powdered tissue using TRIzol Reagent (Invitrogen) according to the manufacturer's protocol. After DNAse treatment (Roche Diagnostics $\mathrm{GmbH}$ ), a total of $30 \mathrm{ng}$ RNA were reverse transcribed with GeneAmp RNA PCR Kit (Perkin Elmer) using random hexamers. Real-time qPCR was performed in a CFX96 Real-time Thermal Cycler (Biorad) applying the CYBR green method. The primer pairs applied are specified in Table 1. PCR was performed in a volume of $20 \mu \mathrm{L}$ using $10 \mu \mathrm{L}$ SYBR Green, $300 \mathrm{nM}$ of each primer and $1 \mu \mathrm{L}$ cDNA. The cycling conditions for amplification included an initial denaturation for $10 \mathrm{~min}$ at $95^{\circ} \mathrm{C}$, followed by 40 cycles at $95^{\circ} \mathrm{C}$ for $15 \mathrm{~s}$ and $60^{\circ} \mathrm{C}$ for $60 \mathrm{~s}$. All samples were run in duplicates. In order to validate the qPCR methods, standard curves were generated by serial dilutions of the cDNA, and their slopes were used to calculate the efficiencies of the PCR reactions, which were between $88.2 \%$ and $106.8 \%$ for the target genes and the two housekeeping genes hypoxanthine-guanine phosphoribosyltransferase (HPRT1) and TATA-binding protein (TBP). RGE values were calculated using the comparative CT method ( $\Delta \Delta \mathrm{CT}$ method) and reported as $\mathrm{n}$-fold differences in comparison to the sample with the lowest amount of the respective target gene transcripts (calibrator) after correction for the efficiency of the PCR reaction and normalizing the samples referring to the two housekeeping genes. For further validation of the qPCR methods, after completion of the amplification a melting curve of the PCR product was generated to test for the occurrence of nonspecific products and primer dimers. Moreover, correct size of PCR products was confirmed by agarose gel electrophoresis.

Depending on the target gene investigated, in part, RGE levels varied extensively between individual animals (Supplementary Table 1, see section on supplementary data given at the end of this article). Thus, in order to demonstrate tissue distribution patterns more recognizably, for each animal and target gene the highest RGE value measured was set to 1 , and the expression levels measured in the remaining tissues of an individual animal are presented relative to the to the tissue sample exhibiting maximal expression (RGE levels scaled to 1). Data from this type of evaluation are inherently limited by the borders 0 and 1 . To avoid error bars exceeding 1 or falling below 0 when combining the data from individual animals, data were transformed by the arc sine function and presented as re-transformed values of mean \pm S.D. of the arc sine transformed values (modified mean \pm S.D. range). 
Table 1 List of primers used in real-time RT-qPCR.

\begin{tabular}{|c|c|c|c|}
\hline \multirow[b]{2}{*}{ Primer } & \multicolumn{2}{|c|}{ Sequence $\left(5^{\prime} \rightarrow 3^{\prime}\right)$} & \multirow{2}{*}{$\begin{array}{l}\text { Product length } \\
\text { (bp) }\end{array}$} \\
\hline & Forward & Reverse & \\
\hline CYP11A1 & CATCAGGGAAGACCTGTTTCG & GGCGCTCTCCAAATATGACATT & 65 \\
\hline CYP17 & GCTCTTGGTTTTCTTCTTGC & ATTCCTTGCCCTTCTTGAG & 269 \\
\hline CYP19* & GATTCCATCACCAAGCACCT & GATCCCCAGGAAGAGGTTGT & 123 \\
\hline HSD3B1 & ATCCACACCAGCAGCATAG & CCAGCACAGCCTTCTCAG & 142 \\
\hline$H S D 17 B 3$ & AGTTTCGCCAAGGTCTTTC & TCCCTATCGTCCACTCAATC & 182 \\
\hline SRD5A2 & GCCTTTTCCAGTTGTATTCC & ACCACTCAGCAGGGTATTC & 107 \\
\hline SULT2A1 & АССТССССАТССААСТСТТС & CTTCTCGTGTCCCGTTTCAG & 283 \\
\hline SULT2B1 & TTGTCAGGCGAATACTTCC & CTTGGGGTAGGTGATGATG & 129 \\
\hline HPRT1 & GCATTCCTGAACTCTTTATTTGCA & TTCACGAGTCAAACAACAATCCA & 80 \\
\hline$T B P$ & TGGTACATTTAATGGTGGTGTTGTG & CCTAAACCGAACGTCCATCCT & 65 \\
\hline
\end{tabular}

Reference or sequence information

Favreau et al. (2009)

M63507.1

NM 214430.1

AF232699.2

NM_001244790.1

AF008440.2

NM_001037150.1

NM_001243697.1

NM 001032376.2

DQ845178.1

*Designed to amplify all three porcine CYP19 isoforms (Conley et al. 2009).

\section{Preparation of cytosolic fractions and homogenates}

For WB analysis and measurements of enzyme activities cytosolic fractions were prepared. Pieces of frozen tissue with a total weight of $0.2 \mathrm{~g}$ were placed with $1 \mathrm{~g}$ ceramic beads (Lysing Matrix D, MP-Biomedicals, Eschwege, Germany) and $1 \mathrm{~mL}$ homogenization medium $(0.1 \mathrm{M}$ potassium phosphate buffer $\mathrm{pH} 7.4$ including $5 \mathrm{mM}$ $\beta$-mercaptoethanol and $20 \%(\mathrm{v} / \mathrm{v})$ glycerol) in $2 \mathrm{~mL}$ Micro Tubes (Sarstedt AG \& Co, Nuembrecht, Germany) and shredded by $2 \times 20$ s bursts using a Fast Prep- 24 homogenizer (MP-Biomedicals, Eschwege, Germany). The resulting suspension was centrifuged for $10 \mathrm{~min}$ at $15000 \mathrm{~g}$ and $4^{\circ} \mathrm{C}$ to remove remaining particles of connective tissue, cellular debris, nuclei and the beads. The supernatants were centrifuged at $100,000 \boldsymbol{g}$ for $1 \mathrm{~h}$ at $4^{\circ} \mathrm{C}$ (L-70 Optima Ultracentrifuge, Beckman Coulter $\mathrm{GmbH}$, Krefeld, Germany). The supernatant (cytosolic fraction) was decanted and protein concentrations were measured using the Pierce BCA Protein Assay Kit (Thermo Fischer Scientific GmbH). Finally, the cytosols were stored at $-20^{\circ} \mathrm{C}$ until further analysis.

As an alternative to cytosols, sulfotransferase activities were also determined in tissue homogenates. Homogenization of tissue samples was performed as described earlier for the preparation of cytosols. However, Ringer solution/50 mmol/L HEPES pH 7.0 was used as a homogenization medium. The resulting crude homogenates were centrifuged at $4^{\circ} \mathrm{C}$ for $35 \mathrm{~min}$ at $20,000 \boldsymbol{g}$ (Biofuge $28 \mathrm{RS}$, Heraeus, Osterode, Germany) and the supernatants were stored at $-20^{\circ} \mathrm{C}$ until further use.

\section{Detection of SULT2A1 and SULT2B1 in cytosolic fractions using Western blot}

Cytosolic samples were separated on a $10 \%$ polyacrylamide gel under reducing conditions and subsequently electroblotted to nitrocellulose membranes (Optitran BA-S85, Schleicher \& Schüll, Dassel, Germany). For blocking, membranes were incubated overnight in PBS-T (PBS with $0.05 \%$ Tween-20) with 5\% nonfat dry milk. They were then washed in PBS-T and incubated for $60 \mathrm{~min}$ with the respective primary antibody (SULT2A1: rabbit polyclonal antibody against a synthetic peptide corresponding to amino acids 253-285 of human SULT2A1, PA5-12243, Fisher Scientific, Schwerte, Germany, dilution: 1:500; SULT2B1: rabbit polyclonal antibody generated against a fragment corresponding to a region within amino acids 20-387 of human SULT2B1; GTX114812, GeneTex, Irvine, CA, USA, dilution 1:2000; alignments of human and porcine amino acid sequences for SULT2A1 and SULT2B1 are presented in Supplementary Figs. 1 and 2 , respectively). After washing in PBS-T, they were incubated for $30 \mathrm{~min}$ with the horseradish peroxidase-linked secondary goat-anti-rabbit immunoglobulin antibody (Dianova, Hamburg, Germany) at a dilution of 1:50,000 in PBS-T. For visualization of the immunoreaction, a chemiluminescence-based method was applied (AceGlow Ultrasensitive Chemiluminescence Substrate, detection of immunoreaction and documentation of results with Fusion Solo VilberLourmat, both from PEQLAB Biotechnologie GmbH, Erlangen, Germany).

Determination of DHEA sulfotransferase (DHEA-ST) and pregnenolone sulfotransferase (P5-ST) activities in cytosolic fractions and tissue homogenates

Measurement of DHEA-ST and P5-ST activities were performed in sample sets prepared from three boars. Cytosolic fractions $(50 \mu \mathrm{L})$ or tissue homogenates $(50 \mu \mathrm{L})$, $250 \mu \mathrm{mol} / \mathrm{L} \quad 3{ }^{\prime}$-phosphoadenosine-5' -phosphosulfate (PAPS, Santa Cruz Biotechnology), $7.5 \mathrm{mmol} / \mathrm{L} \mathrm{MgCl}_{2}$, $16 \mu \mathrm{mol} / \mathrm{L}$ of the steroid sulfatase inhibitor STX64 
(Sigma-Aldrich $\mathrm{GmbH}$ and $0.8 \mu \mathrm{mol} / \mathrm{L}$ of the respective substrate were incubated at $37^{\circ} \mathrm{C}$ for $20 \mathrm{~min}$ in a total volume of $200 \mu \mathrm{L}$ applying Ringer solution $/ 50 \mathrm{mmol} / \mathrm{L}$ HEPES buffer pH 7.0 as an incubation medium. In order to facilitate the determination of substrate conversion and product formation, in addition to the unlabeled substrate, the incubations included a small amount of the corresponding tritiated substrate $(7.5 \mathrm{nmol} / \mathrm{L} 6,7-3 \mathrm{H}(\mathrm{N})$ DHEA, Hartmann Analytic GmbH, Braunschweig, Germany or $15 \mathrm{nmol} / \mathrm{L}$ 7-3H(N)-P5, PerkinElmer). In order to assess substrate conversions unrelated to sulfotransferases, for each sample, parallel incubations were performed in which PAPS was replaced by incubation buffer. Following incubation, the reaction was stopped by addition of $50 \mu \mathrm{L}$ acetonitrile $(\mathrm{ACN})$ and placing the samples on ice. After centrifugation $\left(20,000 \mathrm{~g}, 10 \mathrm{~min}, 4^{\circ} \mathrm{C}\right)$, a $50 \mu \mathrm{L}$ aliquot of the supernatant was separated on a reversed phase column ( $150 \times 4 \mathrm{~mm}$ Eurospher II 100-5 C18 column) in an HPLC system (Smartline Manager 5050 and Pump 150, all HPLC equipment from Knauer, Berlin, Germany) with an ACN/ water gradient (30-70\% during $14 \mathrm{~min}$ ) and a flow rate of $0.5 \mathrm{~mL} / \mathrm{min}$. The eluate was collected in $0.5 \mathrm{~mL}$ fractions, in which ${ }^{3} \mathrm{H}$-activities were measured (Tri-Carb 2810TR, PerkinElmer, Rodgau, Germany) after addition of liquid scintillation fluid (Aquasafe 300 plus, Zinnser Analytic, Frankfurt, Germany). Identification of substrate and metabolites was based on a comparison of the retention times with authentic tritiated standards (Fig. 2A and B for exemplary chromatograms). Conversion of substrate was calculated from the distribution of ${ }^{3} \mathrm{H}$-activity over the peaks of the unconjugated and sulfonated steroid after subtraction of the technical background. Due to the specific features of the method applied for the assessment of enzyme activities, low substrate concentrations relative to enzyme activity could result in virtually complete substrate depletion, whereas high concentrations could lead to product peaks disappearing in the technical background. Thus, the substrate concentration applied was established in preliminary experiments to ensure a sufficient differentiation between the enzyme activities present in the different tissue samples (Fig. 2C).

\section{Immunolocalization of SULT2A1 and SULT2B1}

After $20-24 \mathrm{~h}$ of fixation in 10\% phosphate-buffered formalin and subsequent washing in $0.1 \mathrm{M}$ phosphate buffer $\mathrm{pH} 7.2$ for removal of the fixative, the tissue samples were dehydrated in an ascending ethanol series and embedded in paraffin. Sections $(5 \mu \mathrm{m})$ were prepared and heated in $10 \mathrm{mM}$ citrate buffer $\mathrm{pH} 6.0$ for epitope retrieval
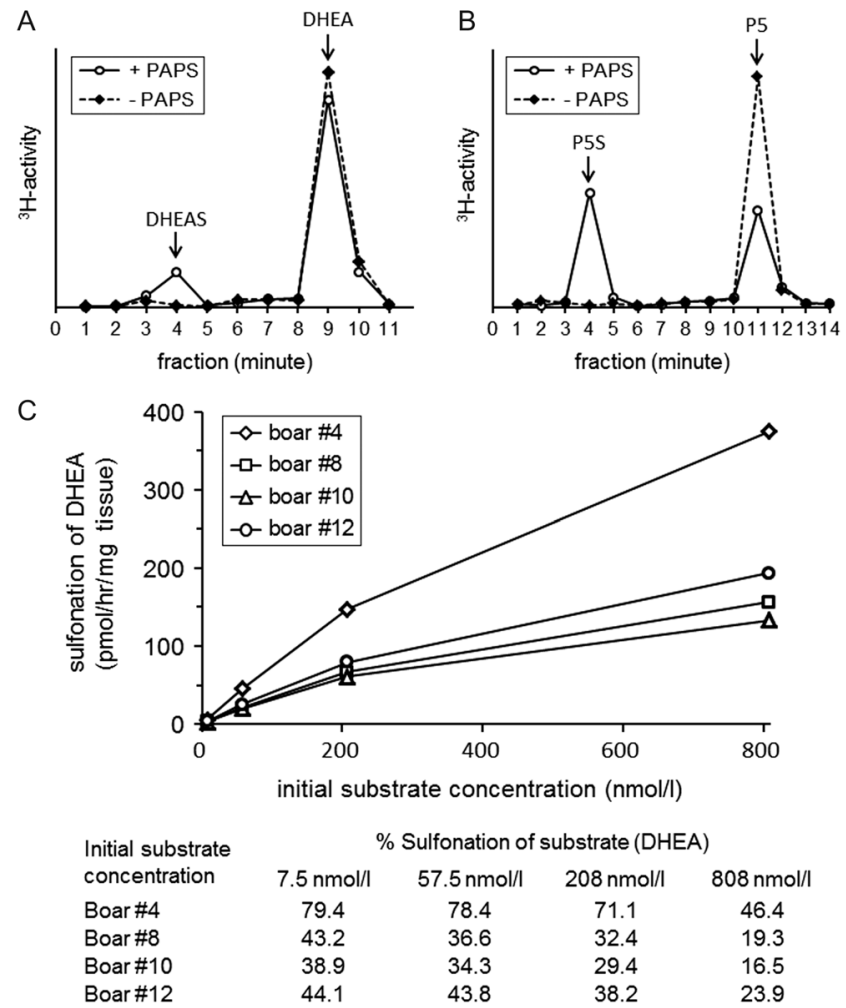

Figure 2

Determination of substrate sulfonation. (A) Exemplary chromatograms obtained after incubation $(20 \mathrm{~min}$ ) of $50 \mu \mathrm{L}$ testicular homogenate (boar \#10) with $0.8 \mu \mathrm{mol} / \mathrm{L}$ DHEA as a substrate in the presence (+) or absence (-) of the sulfotransferase cosubstrate PAPS $(250 \mu \mathrm{mol} / \mathrm{L})$. (B) Exemplary chromatograms obtained after incubation $(20 \mathrm{~min})$ of $50 \mu \mathrm{L}$ epididymal cytosol (sample TL1, boar \#8) with $0.8 \mu \mathrm{mol} / \mathrm{L}$ pregnenolone (P5) in the presence $(+)$ or absence $(-)$ of PAPS $(250 \mu \mathrm{mol} / \mathrm{L})$. Arrows indicate the retention time of authentic tritiated standards (C) Results from a preliminary experiment conducted to establish a suitable substrate concentration for the determination of hydroxysteroid sulfotransferase activities. Testicular homogenates from four boars were incubated for $20 \mathrm{~min}$ in the presence of PAPS $(250 \mu \mathrm{mol} / \mathrm{L})$ with a constant amount of ${ }^{3} \mathrm{H}-\mathrm{DHEA}(7.5 \mathrm{nmol} / \mathrm{L})$ and increasing amounts of unlabeled DHEA $(0,50$, $200,800 \mathrm{nmol} / \mathrm{L})$. Based on the distribution of ${ }^{3} \mathrm{H}$-activity in HPLC chromatograms over the peaks for the substrate and the sulfonated product (see table below the diagram) the reaction rate was calculated.

at temperatures between 98 and $100^{\circ} \mathrm{C}$ for $20 \mathrm{~min}$. Indirect immunoperoxidase staining method were employed using the streptavidin-biotin technique for signal enhancement following standard procedures. Primary antisera were the same as specified for WB. Negative controls were set up replacing the specific antiserum with purified non-immunized rabbit IgG (Life Technologies). Blocking serum, biotinylated secondary antibody and avidin-biotin complex were taken from the Vectastain Elite $\mathrm{ABC}$ kit 6101 and used following the manufacturer's instructions (Vector Laboratories, Burlingame, CA, USA). NovaRed substrate kit (Vector Laboratories) was applied to visualize the immunoreaction. To further corroborate the 
specificity of immunohistochemical method for porcine SULT2B1, a preadsorption test was performed in which the primary antibody working solution was incubated with or without addition of human recombinant SULT2B1b (concentration: $8 \mu \mathrm{g} / \mathrm{mL}$; GenWay Biotech catalog no. GWB-BSP311; distributed by BIOZOL Diagnostica, Eching, Germany) for $24 \mathrm{~h}$ before application to tissue sections prepared from testis and epididymal tail. Additionally, as a positive control, tissue porcine small intestine (ileum) has been used, which has been shown to highly express SULT2B1 in mice and rats (Shimizu et al. 2003, Alnouti \& Klaassen 2006, Kohjitani et al. 2006).

\section{Results}

\section{Expression of SULT2A1}

For SULT2A1-mRNA, the testis was the predominant site of expression (Fig. 3A; Supplementary Table 1). In two of five animals investigated, considerable expression levels were also measured in the middle part of the epididymal body. In the remaining three animals, expression in the epididymal body was substantially lower but still slightly higher compared to the epididymal head and tail. Consistently, when screening the testicular-epididymal compartment from three boars for the expression of the protein by WB applying cytosol specific bands exhibiting the expected molecular weight of $34 \mathrm{kDa}$ were detected in the testis and epididymal samples EB2 and/or EB3 (Fig. 3B; see also Supplementary Fig. 3A). Sample B4 was omitted in these experiments to include liver as a positive control, in which a specific band of high intensity occurred. In an additional experiment, testicular samples from five boars were investigated in one analytical process also including the liver sample (Fig. 3C). Again, in the liver, a band of considerable intensity was found, whereas intensity in testicular samples was lower and exhibited a substantial variability between individual animals. By means of IHC, in porcine liver used as a positive control tissue, a distinct to intense cytoplasmic staining occurred in virtually all hepatocytes, whereas no considerable staining was observed in other cell types (Fig. 4A). In negative controls (Fig. 4B), no noteworthy staining was found. Complete sample sets from three boars were immunostained and visually evaluated. In the testis (Fig. 4C), a weak-todistinct cytoplasmic staining occurred in practically all Leydig cells. Moreover, in a variable proportion of Leydig cells in addition to cytosolic staining, a weak to distinct nuclear staining was visible, which however was considered nonspecific (see Discussion section). Negative

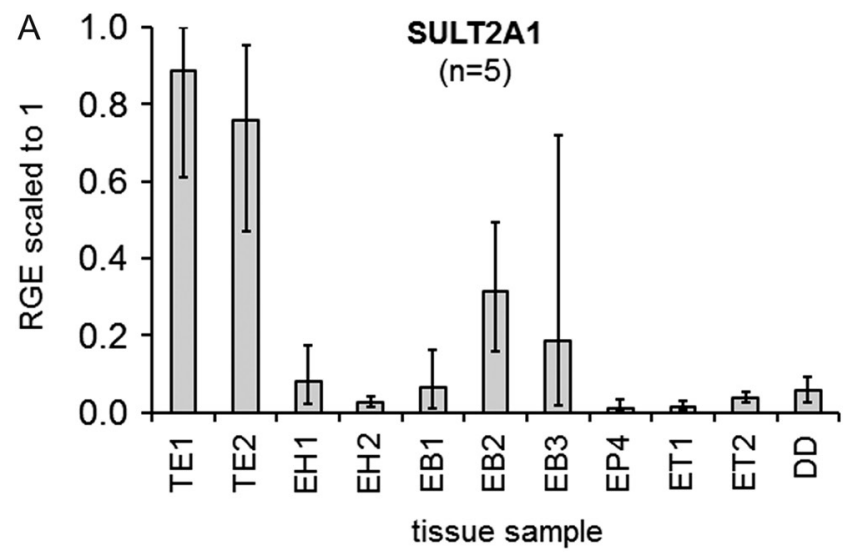

B MW TE2 EH1 EH2 EB1 EB2 EB3 ET1 ET2 L

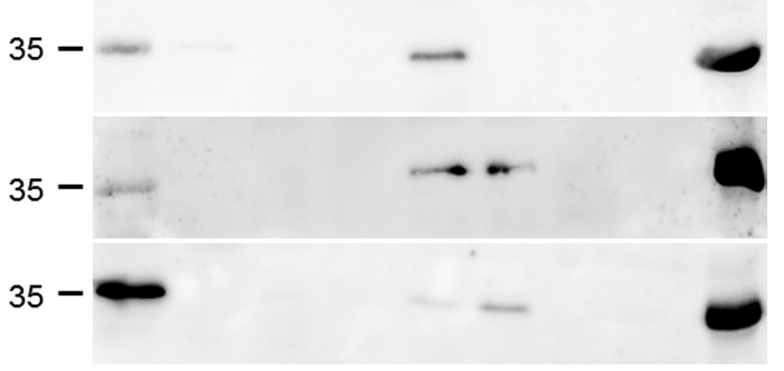

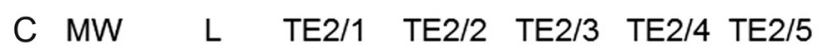

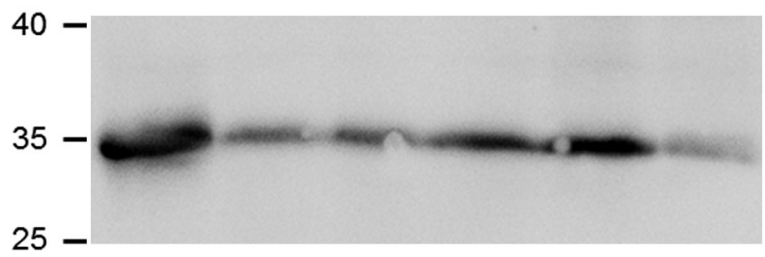

Figure 3

Expression of SULT2A1 in the porcine testicular-epididymal compartment. (A) SULT2A1-mRNA expression based on RGE levels measured in five sexually mature boars by semi-quantitative real-time RT-qPCR (Supplementary Table 1). For each animal, the expression level in the tissue sample with the highest RGE value was set to 1 and expression levels of the remaining samples were calculated relative to this sample. The data shown are presented as re-transformed $\bar{x} \pm$ s.D. calculated from arc sine transformed data (modified $\bar{x} \pm$ s.D. range). (B) WB analysis of SULT2A1 expression in three individual boars. Sample EB4 was omitted to include porcine liver (L) as a positive control. In each lane, $30 \mu \mathrm{g}$ cytosolic protein was loaded. (C) Comparison of SULT2A1 expression between testicular tissue from five boars (TE2/1-TE2/5) and liver (L). In each lane, $20 \mu \mathrm{g}$ cytosolic protein was loaded. Tissue samples: TE1,-2: upper/lower half of testis; EH1,-2: proximal and distal part of the epididymal head; EB1-4: segments of the epididymal body, from proximal to distal; ET1,-2: proximal and distal part of the epididymal tail; DD: deferent duct.

controls were devoid of noteworthy staining (Fig. 4D). Also in the epididymis (Fig. 4E and F), a weak-to-moderate nuclear staining considered nonspecific was found in the ductal epithelium throughout the organ with decreasing intensity from head to tail. Specific cytoplasmic staining 

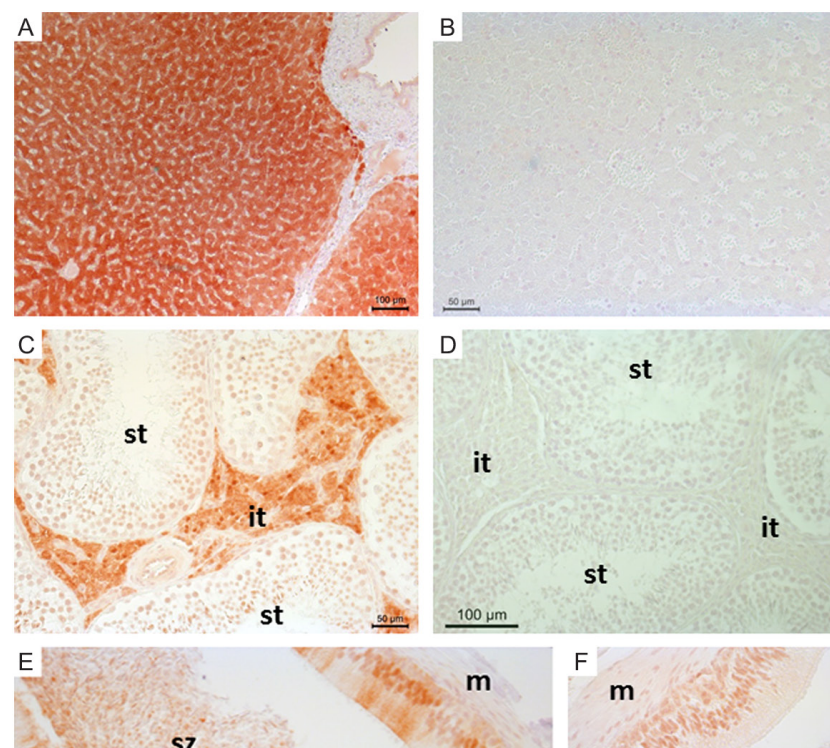

SZ

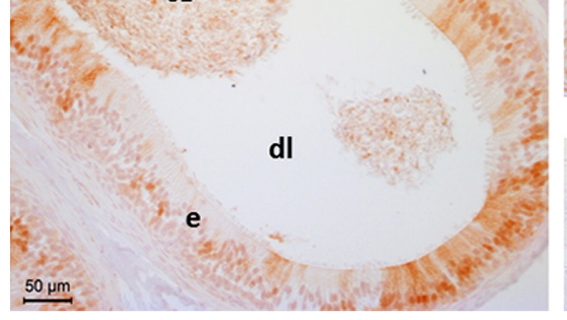

st

it

it

st

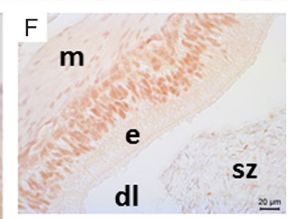

G

dl

e

m

\section{Figure 4}

Immunolocalization of SULT2A1 in the porcine testis and epididymis. (A) Immunostaining in porcine liver used as a positive control. (B) Negative control (porcine liver). (C) Immunostaining in testis. (D) Negative control (testis). (E) Immunostaining in epididymal body (segment EB2). (F) Immunostaining in the distal epididymal body (segment EB4) with moderate nuclear staining of questionable specificity. (F) Negative control (epididymal body, segment EB3). dl, ductal lumen; e, epithelium; it, interstitial tissue; m, muscular layer; st, seminiferous tubules; sz, conglomerates of spermatozoa.

in the ductal epithelium was only weak or absent with the exception of the epididymal body (segments EB1-EB3), where a more pronounced staining occurred in clusters of epithelial cells (Fig. 4E). In addition to the ductal epithelium, immunostaining was observed in spherical particles situated in the ductal lumen and in vascular endothelial cells of the epididymal connective tissue (not shown). Negative controls prepared from epididymal tissue samples were devoid of noticeable staining (Fig. 4G).

\section{Expression of SULT2B1}

SULT2B1-mRNA expression was only minimal in the testis, increased slightly along the initial and middle parts of the epididymis and was considerably higher in the hind part of the epididymal body and in the epididymal tail (Fig. 5A; Supplementary Table 1). In all animals

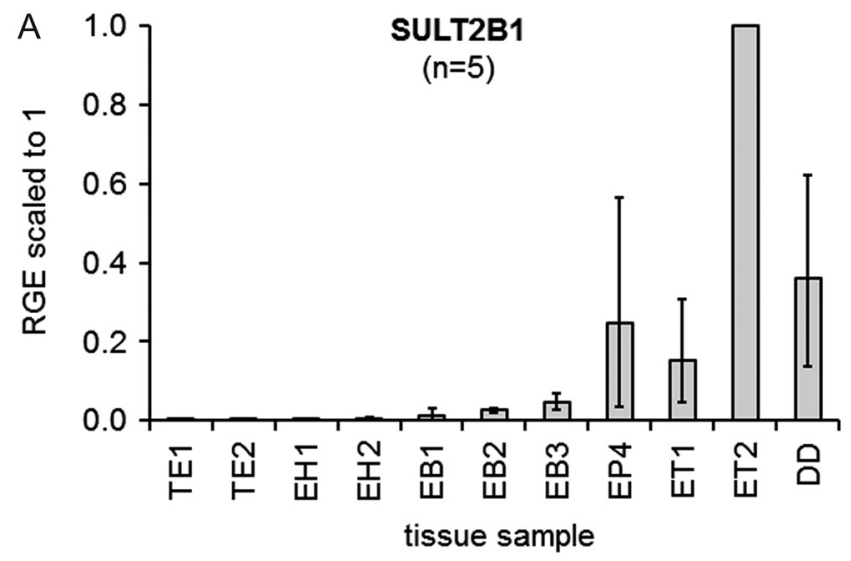

B MW TE2 EH1 EH2 EB1 EB2 EB3 EB4 ET1 ET2

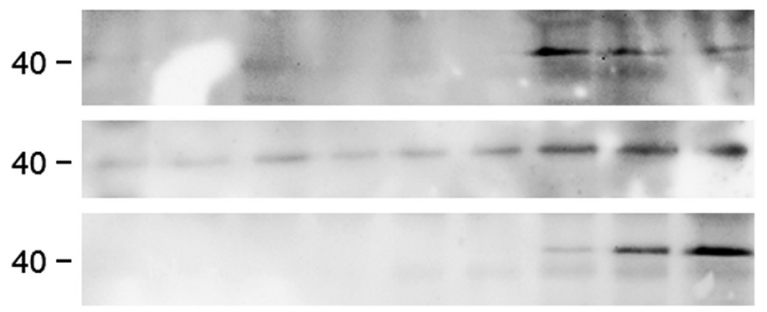

Figure 5

Expression of SULT2B1 in the porcine testicular-epididymal compartment. (A) SULT2B1-mRNA expression based on the relative gene expression levels measured in five sexually mature boars by semi-quantitative real-time RT-qPCR (Supplementary Table 1). For each animal, the expression level in the tissue sample with the highest RGE value was set to 1 and expression levels of the remaining samples are presented relative to this sample. The data shown are presented as re-transformed $\bar{x} \pm$ S.D. calculated from arc sine transformed data (modified $\bar{x} \pm$ S.D. range). (B) WB analysis of SULT2B1 expression in three individual boars. In each lane, $30 \mu \mathrm{g}$ cytosolic protein was loaded. Tissue samples: TE1,-2: upper/lower half of testis; EH1,-2: proximal and distal part of the epididymal head; EB1-4: segments of the epididymal body, from proximal to distal; ET1,-2: proximal and distal part of the epididymal tail; DD: deferent duct.

investigated, SULT2B1-mRNA expression was highest in the distal part of the epididymal tail. Concordant with results from real-time RT-qPCR, in WB applying a primary antiserum against the human enzyme (Fig. 5B; see also Supplementary Fig. 3B) specific bands of variable intensity corresponding to the expected molecular weight of $38.4 \mathrm{kDa}$ were consistently found in samples of the distal epididymal body and in the epididymal tail. In other tissue samples, they were only of weak intensity or absent. In IHC control experiments, a distinct staining was found in epithelial cells of porcine ileum (Fig. 6A) used as a positive control tissue and in ductal epithelial cells of the epididymal tail (Fig. 6B), which almost completely disappeared after preadsorption of the primary antiserum with recombinant human full-length SULT2B1b (Fig. 6C and D). No noteworthy staining was observed in negative 

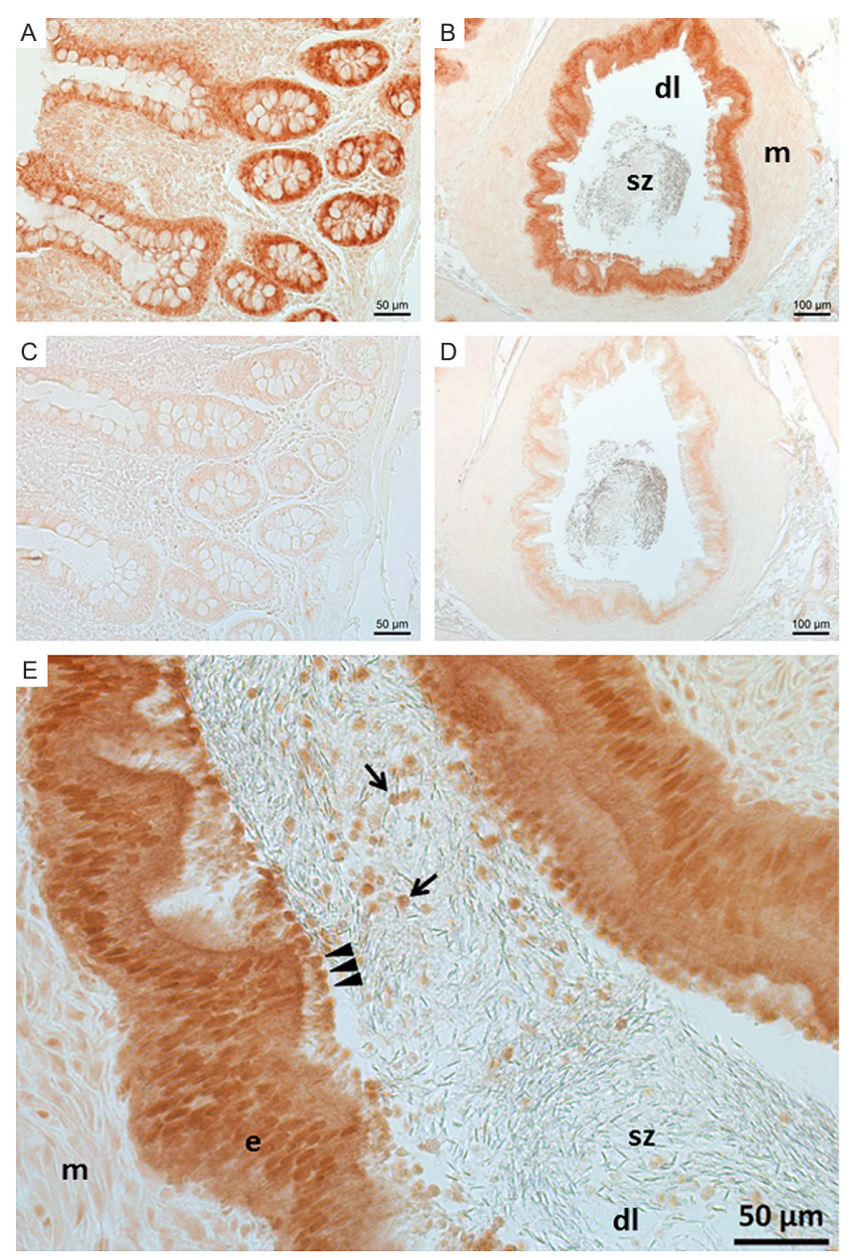

Figure 6

Immunolocalization of SULT2B1. (A, B, C and D) Results from a control experiment. Distinct staining in (A) epithelial cells of ileum (positive control tissue) and (B) in epididymal duct epithelium (sample ET1). (C and D) The same localization as shown in Fig. (A) and (B) when the primary antiserum was preadsorbed with recombinant human SULT2B1. (E) Porcine epididymis (segment ET1); distinct immunostaining of the high ductal epithelium including apical protrusions (arrowheads) and of spherical material situated in the ductal lumen (arrows) between conglomerated spermatozoa. Moderate immunostaining is also present in the muscular layer. dl, ductal lumen; e, epithelium; m, muscular layer; sz, conglomerates of spermatozoa.

controls in which the primary antiserum was replaced by nonspecific rabbit immunoglobulin (not shown). Immunolocalization of SULT2B1 in sample sets from four boars yielded a substantial variability in the overall staining intensity between individual animals. However, the staining pattern was consistent in that staining intensity in the cytoplasm of epididymal epithelial cells increased significantly from virtually negative to moderate in the epididymal head to distinct or intense in the tail (Fig. 6B and E). Frequently but not in all localizations superficial protrusions of epithelial cells exhibited moderate-to-intense staining, and immunostained spherical particles were found in the epididymal lumen (Fig. 6E). Moreover, a weak to moderate staining was partly observed in muscular cells of the epididymal tail (Fig. 6E). Different from the ileum epithelium where staining was exclusively cytosolic (Fig. 6A), in the epididymal duct epithelium in addition to cytoplasmic staining in part also nuclear signals were observed (Fig. 6B and E). In testicular samples from all four animals investigated nuclear staining was present in the vast majority of germ cells with the exception of elongating spermatids and sperm cells (not shown), which was only weak in one animal but distinct to intense in the remaining three boars. However, nuclear staining in the testis and epididymis was considered as an artifact (see Discussion section). In liver, no reliable staining occurred (not shown).

\section{Activities of DHEA-ST and P5-ST}

In preliminary experiments, sulfonation of DHEA in testicular cytosols from five boars was, if at all, only minimal $(3.4 \pm 2.0 \%)$, and no conversion exceeding background levels was found in epididymal samples (not shown). Moreover, in testicular cytosols, no considerable sulfonation of DHEA was observed even after supplementation of the incubation medium with

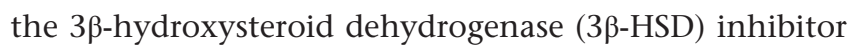
trilostane (data not shown). When measuring DHEA-ST activity in tissue homogenates (Fig. 7A), a variable but significant sulfonation of DHEA was detected in testicular samples (see also Fig. 2A and C). In epididymal samples, DHEA-ST activities were low in the head and in the proximal part of the body. In the distal body and tail, activities were in a similar range as observed in testicular samples, again with a considerable variability between individual animals and also between different segments of the organ.

When measuring P5-ST activities in cytosols (Fig. 7B), conversion rates of the substrate was only marginal in testis, epididymal head and the initial segment of the epididymal body. They increased in the subsequent segments of the epididymal body and were maximal in the epididymal tail. When measuring the sulfonation of P5 in homogenates prepared from the testis and selected segments (EH1, ET1) of the epididymis (Fig. 7C), as in cytosols sulfonation activities were high in epididymal tail and only marginal in epididymal head. However, different from the results obtained with cytosols, in testicular samples, a substantial sulfonation of P5 was observed. 
A

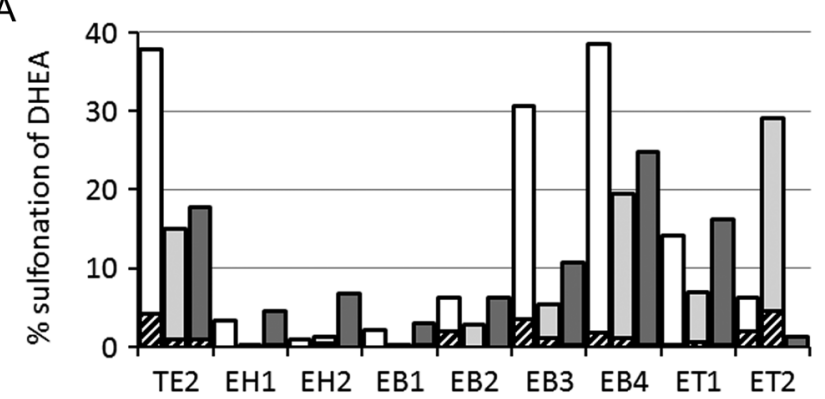

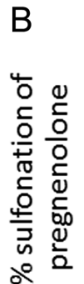

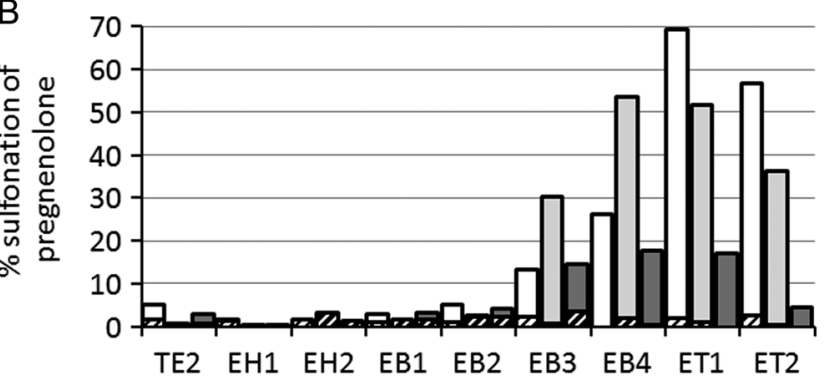

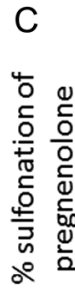

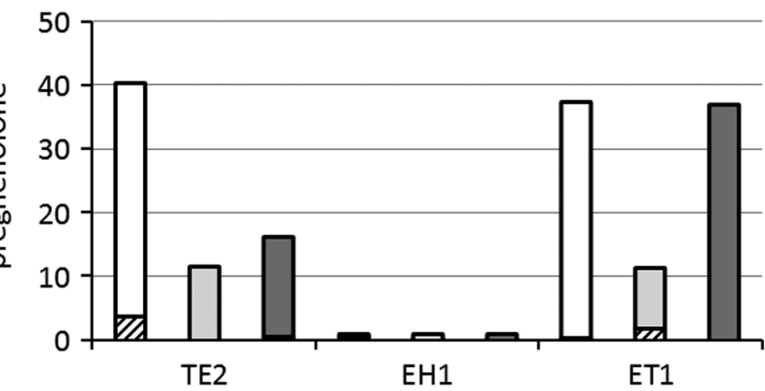

Figure 7

Assessment of DHEA and pregnenolone sulfotransferase activities in the porcine testis and epididymis. (A) Sulfonation of DHEA by homogenates $(50 \mu \mathrm{L})$ prepared from testis and epididymal segments of three individual boars ( $\# 4, \# 10, \# 12)$. (B) Sulfonation of pregnenolone by cytosols $(50 \mu \mathrm{L})$ prepared from testis and epididymal segments of three individual boars $(\# 4, \# 8, \# 9)$. (C) Sulfonation of pregnenolone by homogenates $(50 \mu \mathrm{L})$ prepared from selected tissue samples of three individual boars (\#4, \#10, $\# 12$ ). In all experiments, initial substrate concentration was $0.8 \mu \mathrm{mol} / \mathrm{L}$ and the time of incubation was $20 \mathrm{~min}$. Hatched bars indicate substrate conversion in the absence of the sulfate donor PAPS. Tissue samples: TE2: testis (lower half); EH1,-2: proximal and distal part of the epididymal head; EB1-4: segments of the epididymal body, from proximal to distal; ET1,-2: proximal and distal part of the epididymal tail.

\section{Relative expression levels of mRNA encoding important steroidogenic enzymes}

RGE levels scaled to 1 are presented in Fig. 8, whereas information on original RGE levels is included in Supplementary Table 1. For CYP11A1 (side-chain cleavage enzyme), CYP17A1 (17 $\alpha$-hydroxylase-C17,20-lyase), CYP19 (aromatase; all three porcine isoforms) and HSD17B3 (17ß-hydroxysteroid dehydrogenase isoform 3) from a
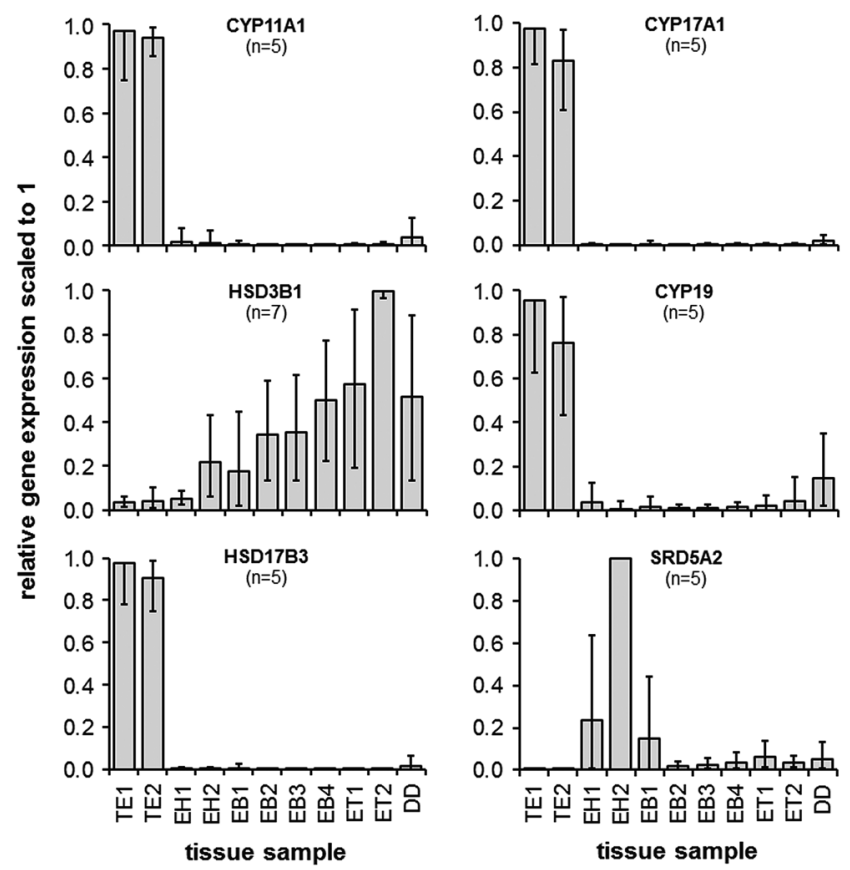

Figure 8

Expression levels of mRNA encoding important steroidogenic enzymes in the porcine testis, different segments of the epididymis and in the DD. The data shown are based on the relative gene expression (RGE) levels measured in 5-7 sexually mature boars by semi-quantitative real-time RT-qPCR (Supplementary Table 1). For each animal, the expression level in the tissue sample with the highest RGE value was set to 1 and expression levels of the remaining samples are presented relative to this sample. The data shown are presented as re-transformed $\bar{x} \pm$ s.D. calculated from arc sine transformed data (modified mean \pm S.D. range). Tissue samples: TE1,-2: upper/lower half of testis; EH1,-2: proximal and distal part of the epididymal head; EB1-4: segments of the epididymal body, from proximal to distal; ET1,-2: proximal and distal part of the epididymal tail; DD: deferent duct.

quantitative point of view, the testis was clearly identified as the only significant tissue of expression. Expression levels of HSD3B1 (3ß-hydroxysteroid dehydrogenase$\Delta 5 / 4$-isomerase) were relatively low in the testis, increased continuously along the epididymis and were maximal in the tail. RGE levels exhibited a considerable variability between individual animals as indicated by high deviation factors (Supplementary Table 1). SDR5A2 (5 $\alpha$-reductase isoform 2) was specifically expressed in the head and the initial segment of the epididymal body.

\section{Discussion}

SULTs 2A1 and 2B1 have been identified in humans (Falany et al. 1995, Strott 2002, Gamage et al. 2006, Dawson 2012, Pasqualini 2009, Mueller et al. 2015) and laboratory rodents (Shimizu et al. 2003, Kohjitani et al. 2006) as the relevant sulfotransferases for neutral 
hydroxysteroids. Some studies have been conducted concerning the expression of these SULTs in the porcine testis and liver focusing on a putative role as genetic markers for selecting animals with low boar taint, however, with partly inconsistent results (Sinclair et al. 2006, Moe et al. 2007a,b, 2008, Grindflek et al. 2010, Rasmussen et al. 2012). So far, no information was available at all on the expression of SULT2A1 and SULT2B1 in the porcine epididymis and hydroxysteroid sulfotransferase activities in this organ, and no observations have been reported from immunohistochemistry for the porcine testis and epididymis with respect to the two enzymes.

\section{Expression of SULT2A1}

When screening the porcine testis for the expression of SULT2A1, consistent with earlier studies (Sinclair et al. 2006), a considerable expression was found on the mRNA level by real-time RT-qPCR and on the protein level by WB. With IHC in the testis, immunostaining was restricted to Leydig cells. However, different from hepatocytes where immunostaining was exclusively cytoplasmic, in a significant proportion of Leydig cells in addition to cytoplasmic staining nuclear signals of variable intensity occurred. As SULTs are generally considered as cytoplasmic enzymes, the authenticity of nuclear signals must be questioned although in humans, a nuclear localization has been described for SULT2B1 in certain cell types (see Discussion below concerning SULT2B1). However, so far, no nuclear localization has been reported for SULT2A1. In the epididymis, with WB SULT2A1 expression was exclusively detected in the mid-region of the epididymal body, which corresponded to higher RGE expression levels obtained with real-time RT-qPCR in comparison to other epididymal segments. Consistently, with IHC, a moderate-to-distinct cytoplasmic staining was observed specifically in the epididymal body, where the presence of immunostained spherical particles in the ductal lumen suggests that the enzyme was secreted into luminal compartment (see also Discussion below for SULT2B1). The role of SULT2A1 expressed in a relatively restricted part of the epididymal ductal epithelium remains unclear given the broad spectrum of potential steroidal and nonsteroidal substrates. In addition to the cytoplasmic staining observed in the epididymal body, in the epithelium of the epididymal duct, a weak-tomoderate nuclear staining was present throughout the organ. However, as discussed earlier, it was considered nonspecific.

\section{Expression of SULT2B1}

Expression pattern of SULT2B1 in the porcine testicularepididymal compartment was found to be clearly different from SULT2A1, which is consistent with the tissue selectivity for the expression of only one of the SULT2 genes observed in humans (Falany \& Rohn-Glowacky 2013). In boars, relative SULT2B1-mRNA expression was only minimal in testis and epididymal head, increased gradually in the initial segments of the epididymal body to reach maximum levels in the hind part of the epididymal body and in the tail. Corresponding results were obtained with WB. The fact that the molecular weight of the band detected was slightly below $40 \mathrm{kDa}$ provided clear evidence for the specificity of the antiserum applied for porcine SULT2B1 in WB as this SULT has a clearly higher molecular weight compared to other structurally closely related members of the SULT superfamily. In humans, two SULT2B1 isoforms have been identified on the mRNA level corresponding to 350 (SULT2B1a) and 365 amino acids (SULT2B1b). However, on the protein level, so far only the expression of $S U L T 2 B 1 b$ has been confirmed (Falany \& Rohn-Glowacki 2013). In the pig, to date, only one SULT2B1 isoform of 338 amino acids has been identified (GenBank accession no. NM_001243697.1; for alignment of amino acid sequences see Supplementary Fig. 2), which is consistent with the molecular weight observed in our WB experiments (Fig. 5B and Supplementary Fig. 3B). When screening the testicular-epididymal compartment for SULT2B1 expression by IHC, a good correlation was found between cytoplasmic immunostaining and results from WB and real-time RT-qPCR. In the epididymis, occasionally immunostaining was especially prominent in the apical part of epithelial cells and their superficial protrusions consisting of an apical bleb connected to the cell surface with a cytoplasmic stalk. These apical blebs have been observed to detach into the ductal lumen without damage to the cell as a mechanism of apocrine secretion (Dacheux et al. 2005, Hughes \& Berger 2015). Accordingly, at these localizations, immunostained spherical material with a diameter of up to approximately $5 \mu \mathrm{m}$ could be found in the ductal lumen (Fig. 6E). Similar observations were made by Frenette et al. (2009) when characterizing the expression of SULT1E1 in the bovine epididymis. Based on their observations, they suggested that SULT1E1 is transferred to sperm cells via the inclusion into epididymosomes.

When screening the porcine testis for SULT2B1 expression, depending on the individual animal, a weakto-intense nuclear immunostaining occurred in the 
majority of germ cells (not shown). Moreover, significant nuclear staining also occurred in individual epididymal samples. Human SULT2B1b is the only SULT for which, in selected tissues, a nuclear localization has been described, which has been so far only been reported in human syncytiotrophoblast and in normal and malignant breast tissue. It has been suggested that the nuclear localization of human SULT2B1 in specific tissues is mediated by its unique carboxy terminal tail, which is also involved in post-translational modification, protein interactions and enzyme stability (He et al. 2004, Falany et al. 2006, He \& Falany 2006, Falany \& Rohn-Glowacki 2013). However, although human and porcine SULT2B1 share a high overall identity (75\%) and similarity (84\%), the carboxy terminal tail of porcine SULT2B1 is considerably shorter compared to human SULT2B1 (for comparison of amino acid sequences see Supplementary Fig. 2). As stated on the datasheet provided by the supplier, the primary antiserum used in this study was generated by immunization against a recombinant protein encompassing a proprietary sequence within the center region of human SULT2B1 and was purified by affinity chromatography. Preadsorption of the antiserum with recombinant human full-length SULT2B1b not only abolished cytosolic staining in porcine ileum and epididymis (Fig. 6A, B, C and D) but also significantly reduced nuclear staining in germ cells (not shown) and epididymal duct epithelium (Fig. 6D). This result clearly shows that nuclear staining is related to the primary antibody. However, cross-reactivity with epitopes unrelated to the target molecule, which can be highly specific and limited to one tissue, has been observed even with monoclonal antibodies. Moreover, cross-reacting epitopes may be created during formalin fixation, which can result in diverging results in WB and IHC (Holmseth et al. 2012). The fact that partly intense nuclear staining without concomitant cytosolic signals occurred in a high proportion of germ cells in the presence of only marginal testicular SULT2B1-mRNA expression clearly challenges the authenticity of nuclear staining observed in the porcine testis and epididymis. However, further studies are needed to definitely clarify this issue.

Our observations of a marginal or absent expression of SULT2B1 in the porcine liver and testis are clearly conflicting with results by Moe et al. (2007a), who applied a polyclonal antiserum against an epitope mapping at the C-terminus of human SULT2B1 to detect the enzyme in WB. When analyzing cytosolic preparations from porcine liver and testis, they found bands considered specific in both organs exhibiting a molecular weight of $45 \mathrm{kDa}$. However, our results are consistent with observations in humans, rats and mice, where no quantitatively significant SULT2B1 expression was detectable in these organs (Her et al. 1998, Javitt et al. 2001, Meloche \& Falany 2001, Shimizu et al. 2003, Alnouti \& Klaassen 2006, Kohjitani et al. 2006). Information on SULT2B1 expression in epididymis is currently very sparse. Only one paper was found addressing epididymal SULT2B1 expression demonstrating that in mice, the epididymis is among the organs exhibiting the highest expression levels (Sakakibara et al. 1998).

\section{Hydroxysteroid sulfotransferase activities}

Information on the activities of human SULTs 2A1 and 2B1 indicate overlapping substrate specificities concerning hydroxysteroids, with a clearly broader specificity of SULT2A1 and a specificity more restricted to $3 \beta$-hydroxy-5-ene steroids of SULT2B1. Commonly DHEA is regarded as a prototypical substrate of SULT2A1, whereas P5 was shown to be an efficient substrate of both human SULT2B1 isoforms (Strott 2002). In order to characterize hydroxysteroid sulfotransferase activities in the testis and epididymis initially cytosolic preparations were incubated applying DHEA and P5 as substrates. Considerable sulfonation of P5 was detected in the hind part of the epididymal body and in the tail reminiscent of the expression pattern found for SULT2B1 in real-time RT-qPCR and WB.

When starting preliminary experiments on DHEA-ST activities using cytosols, considerable activities were expected in testicular samples based on our results on SULT2A1 expression from real-time RT-qPCR, WB and IHC and on previous observations by other researchers on DHEA sulfonation in porcine testicular cytosol (Cooke et al. 1983, Sinclair et al. 2006) or preparations obtained after chromatography of cytosol prepared from purified porcine Leydig cells (Hobkirk et al. 1989). However, ${ }^{3} \mathrm{H}$-activities associated with the DHEAS peak were only slightly above the background in the chromatograms. The reason for the unexpectedly low DHEA-ST activities in our cytosolic samples remains unclear. However, the detection of sulfotransferase activities in tissue samples is not trivial as indicated by the fact that it was the loss of enzyme activity during tissue processing or lysis of cells due to unidentified causes, which has significantly hampered the identification of SULT2B1 in humans, and also for the rat and mouse SULT2B1 there are no reports of the isolation of enzymatically active tissue preparations (Falany et al. 2006, Falany \& Rohn-Glowacki 2013). Although similar problems have not been reported on SULT2A1 activity, it 
cannot be ruled out that DHEA-ST activity was widely lost due to the lack of factors stabilizing enzyme activity during tissue processing or the presence of molecules interfering with the active conformation of the enzyme, substrate binding or its interaction with the sulfate donor PAPS under the specific conditions applied. A possible reason for the higher activities found in tissue homogenates could be the application of a different buffer during tissue disruption.

When using tissue homogenates, a considerable sulfonation of DHEA occurred in the testis and the distal segments of the epididymis. Moreover, with this assay system in testicular samples, a considerable sulfonation of P5 was observed, which was not the case with testicular cytosols. This observation points to SULT2A1 as the relevant enzyme for the sulfonation of P5 in the porcine testis. Taken together, the observations from the hydroxysteroid sulfotransferase assays suggest that in our assay system including homogenates both enzymes were active sulfonating both substrates, whereas the conditions of the assay system including cytosol only allowed the considerable sulfonation of P5 by SULT2B1. However, this interpretation needs further confirmation as to date the exact substrate specificities of porcine SULT2A1 and $2 \mathrm{~B} 1$ are virtually unknown and contributions from other SULTs to the conversions observed cannot be excluded. Howsoever, the low substrate conversions in the absence of PAPS in control experiments provide clear evidence that the products formed in our activity assays were primarily sulfonated steroids.

The SULT2B1 expression pattern found in the porcine testis and epididymis is very similar to the distribution of 'steroid sulfotransferase' described in the male hamster reproductive tract, which has been used as a model to study the biochemistry of sterol sulfates found at high concentrations in semen (Bouthillier et al. 1984, Roberts 1987). Consistent with our findings in boars, enzyme activity in hamsters, which was measured as sulfonation of DHEA or desmosterol, increased substantially along the epididymis, whereas it was minimal in the testis. Moreover, consistent with our immunohistochemical observations, also in hamster, the sulfotransferase appeared to be secreted into the luminal fluid (Bouthillier et al. 1984, Roberts 1987). Sterol sulfates avidly taken up by spermatozoa are considered as potent and specific inhibitors of acrosin providing protection against the premature release of acrosomal proteolytic activity (Roberts 1987, Keber et al. 2013). Accordingly, sulfonated cholesterol and desmosterol have been reported as potent inhibitors of porcine acrosin (Burck \& Zimmerman 1980).
Our observations indicate that in boars, SULT2B1 could be the enzyme predominantly underlying this epididymal sulfotransferase activity.

\section{Expression of mRNA encoding important steroidogenic enzymes in the epididymis}

Investigations into epididymal steroid metabolism so far mainly focused on the conversion of testosterone into $5 \alpha$-dihydrotestosterone (DHT) by $5 \alpha$-reductase isoenzymes SRD5A1 and -2 (Pujol \& Bayard 1978, Mahony et al. 1998, Robaire \& Henderson 2006). Otherwise, there are only a very few reports in the literature addressing the steroidogenic capacity of the epididymis (Wiszniewska 2001, 2002, Gorowska et al. 2014). In porcine epididymis, RGE levels for CYP11A1, CYP17A1, CYP19 and HSD17B3 were only low in comparison to testis. Our results concerning the expression of SRD5A2 in the epididymis are consistent with observations in the rat of a high expression in the epididymal head but considerably lower expression levels in the subsequent parts of the organ (Normington \& Russel 1992, Robaire \& Henderson 2006) but are clearly different from the equine epididymis where SRD5A2 expression was virtually undetectable (Corbin et al. 2016). The low SRD5A2 expression found in the porcine testis is in accordance with earlier observations (Robic et al. 2014).

A very intriguing finding was the considerable expression of HSD3B1-mRNA in the epididymis, which clearly exceeded the levels measured in testis. Identical results were obtained in preliminary experiments applying a different primer pair (data not shown). To our knowledge, no corresponding observations have been made so far in pigs or any other species. When in a pilot study, 3 $\beta$-HSD activity was measured in epididymal microsomes applying P5 as a substrate, a highly variable but significant formation of progesterone was found (data not shown). However, despite the low RGE levels found in testicular samples, enzyme activities in the testis were in a similar range compared to the epididymal tail, suggesting that the ratio between RGE levels and enzyme activity differs significantly between the two organs. Alternatively, different isoenzymes could be active in the testis and epididymis. Interestingly, in the porcine testis, evidence for separate $3 \beta$-hydroxysteroid dehydrogenase$\Delta 5 / 4$-isomerases has been reported for the synthesis of androgens and $\Delta 16$-androstenes (Cooke 1996). However, to date, in pigs, only HSD3B1 and HSD3B7 have been identified of which the latter is obviously unrelated to testicular steroidogenesis (Shea et al. 2007). The relevant 
substrates and the role of HSD3B1 highly expressed in the porcine epididymis remain to be elucidated.

\section{Conclusions}

This study confirms that in the porcine testis SULT2A1 is expressed in Leydig cells and shows that they are the only cell type of the organ exhibiting a detectable expression of this multispecific SULT. Observations on SULT2A1 and SULT2B1 expression suggest that in the porcine testis, SULT2A1 is probably the relevant SULT for the synthesis of most, possibly all, sulfonated neutral steroids produced in the organ. The reason why in the porcine Leydig cells, numerous hydroxysteroids are removed from the pool of unconjugated steroids immediately after their synthesis remains to be elucidated. However, sulfonation may be a regulatory mechanism to maintain steroid homeostasis in the course of the substantial diurnal fluctuations of porcine testicular steroidogenesis (Schuler et al. 2018a, 2018b). SULT2A1 and SULT2B1 are both expressed in the porcine epididymis, with SULT2A1 expression focusing on the epididymal body and SULT2B1 expression on the tail, suggesting different functions. The substrates and the roles of SULT2A1 and SULT2B1 in the porcine epididymis are unclear. However, considering sporadic observations on epididymal steroid sulfotransferase activities in other species especially SULT2B1 could serve the production of sterol sulfates, which have been proposed to act as membrane stabilizers and acrosin inhibitors in sperm cells. A surprising observation during this study was the high expression of HSD $3 B 1$ in the porcine epididymis, which deserves further investigation.

\section{Supplementary data}

This is linked to the online version of the paper at https://doi.org/10.1530/ JME-17-0277.

\section{Declaration of interest}

The authors declare that there is no conflict of interest that could be perceived as prejudicing the impartiality of the research reported.

\section{Funding}

Supported by the German Research Foundation (DFG; SCHU 1195/4-2) within the research group 'Sulfated Steroids in Reproduction' (FOR1369).

\section{Acknowledgements}

The authors are very grateful to the Institute of Veterinary Pathology, Justus-Liebig-University, Giessen, Germany for the embedding of tissue samples.

\section{References}

Alnouti Y \& Klaassen CD 2006 Tissue distribution and ontogeny of sulfotransferase enzymes in mice. Toxicological Sciences 93 242-255. (https://doi.org/10.1093/toxsci/kfl050)

Baulieu EE, Fabre-Jung I \& Huis in't Veld LG 1967 Dehydroepiandrosterone sulfate: a secretory product of the boar testis. Endocrinology 81 34-38. (https://doi.org/10.1210/endo-81-1-34)

Bouthillier M, Bleau G, Chapdelaine A \& Roberts KD 1984 Distribution of steroid sulfotransferase in the male hamster reproductive tract. Biology of Reproduction 31 936-941. (https://doi.org/10.1095/ biolreprod31.5.936)

Burck PJ \& Zimmerman RE 1980 The inhibition of acrosin by sterol sulphates. Journal of Reproduction and Fertility 58 121-125. (https:// doi.org/10.1530/jrf.0.0580121)

Claus R \& Hoffmann B 1980 Oestrogens, compared to other steroids of testicular origin, in blood plasma of boars. Acta Endocrinologica 94 404-411.

Cooke GM 1996 Differential effects of trilostane and cyanoketone on the $3 \beta$-hydroxysteroid dehydrogenase-isomerase reactions in androgen and 16-androstene biosynthetic pathways in the pig testis. Journal of Steroid Biochemistry and Molecular Biology 58 95-101. (https://doi.org/10.1016/0960-0760(96)00002-7)

Cooke GM, Ferguson SE, Rytina E \& Gower DB 1983 Properties of porcine liver and testicular steroid sulphotransferases: reaction conditions and influence of naturally occurring steroids and steroid sulphates. Journal of Steroid Biochemistry 19 1103-1109. (https://doi. org/10.1016/0022-4731(83)90403-X)

Conley AJ, Corbin CJ \& Hughes AL 2009 Adaptive evolution of mammalian aromatases: lessons from Suiformes. Journal of Experimental Zoology Part A: Ecological and Integrative Physiology $\mathbf{3 1 1}$ 346-357. (https://doi.org/10.1002/jez.451)

Corbin CJ, Legacki EL, Ball BA, Scoggin KE, Stanley SD \& Conley AJ 2016 Equine $5 \alpha$-reductase activity and expression in epididymis. Journal of Endocrinology 231 23-33. (https://doi.org/10.1530/JOE-160175)

Dacheux JL, Castella S, Gatti JL \& Dacheux F 2005 Epididymal cell secretory activities and the role of proteins in boar sperm maturation. Theriogenology 63 319-341. (https://doi.org/10.1016/j. theriogenology.2004.09.015)

Dawson PA 2012 The biological roles of steroid sulfonation. In Steroids - from Physiology to Clinical Medicine, pp 45-64. Ed SM Ostojic. Rijeka: Intech.

Falany CN \& Rohn-Glowacki KJ 2013 SULT2B1: unique properties and characteristics of a hydroxysteroid sulfotransferase family. Drug Metabolism Reviews 45 388-400. (https://doi.org/10.3109/03602532.2 013.835609)

Falany CN, Comer KA, Dooley TP \& Glatt H 1995 Human dehydroepiandrosterone sulfotransferase. Purification, molecular cloning, and characterization. Annals of the New York Academy of Sciences 774 59-72. (https://doi.org/10.1111/j.1749-6632.1995. tb17372.x)

Falany CN, He D, Dumas N, Frost AR \& Falany JL 2006 Human cytosolic sulfotransferase 2B1: isoform expression, tissue specificity and subcellular localization. Journal of Steroid Biochemistry and Molecular Biology 102 214-221. (https://doi.org/10.1016/j.jsbmb.2006.09.011)

Favreau F, Rossard L, Zhang K, Desurmont T, Manguy E, Belliard A, Fabre S, Liu J, Han Z, Thuillier R, et al. 2009 Expression and modulation of translocator protein and its partners by hypoxia reoxygenation or ischemia and reperfusion in porcine renal models, American Journal of Physiology: Renal Physiology 297 F177-F190. (https://doi.org/10.1152/ajprenal.90422.2008)

Frenette G, Leclerc P, D'amours O \& Sullivan R 2009 Estrogen sulfotransferase is highly expressed along the bovine epididymis and is secreted into the intraluminal environment. Journal of Andrology 30 580-589. (https://doi.org/10.2164/jandrol.108.006668) 
Gamage N, Barnett A, Hempel N, Duggleby RG, Windmill KF, Martin JL \& McManus ME 2006 Human sulfotransferases and their role in chemical metabolism. Toxicological Sciences 90 5-22. (https://doi. org/10.1093/toxsci/kfj061)

Gorowska E, Zarzycka M, Chojnacka K, Bilinska B \& Hejmej A 2014 Postnatal exposure to flutamide affects CDH1 and CTNNB1 gene expression in adult pig epididymis and prostate and alters metabolism of testosterone. Andrology 2 186-197. (https://doi. org/10.1111/j.2047-2927.2013.00172.x)

Gower DB, Harrison FA \& Heap RB 1970 The identification of C19-16unsaturated steroids and estimation of 17-oxosteroids in boar spermatic vein plasma and urine, Journal of Endocrinology $\mathbf{4 7}$ 357-365. (https://doi.org/10.1677/joe.0.0470357)

Grindflek E, Berget I, Moe M, Oeth P \& Lien S 2010 Transcript profiling of candidate genes in testis of pigs exhibiting large differences in androstenone levels. BMC Genetics 11 4. (https://doi. org/10.1186/1471-2156-11-4)

He D \& Falany CN 2006 Characterization of proline-serine-rich carboxyl terminus in human sulfotransferase 2B1b: immunogenicity, subcellular localization, kinetic properties, and phosphorylation. Drug Metabolism and Disposition 34 1749-1755. (https://doi. org/10.1124/dmd.106.011114)

He D, Meloche CA, Dumas NA, Frost AR \& Falany CN 2004 Different subcellular localization of sulfotransferase $2 \mathrm{~B} 1 \mathrm{~b}$ in human placenta and prostate. Biochemical Journal 379 533-540. (https://doi. org/10.1042/bj20031524)

Her C, Wood TC, Eichler EE, Mohrenweiser HW, Ramagli LS, Siciliano MJ \& Weinshilboum RM 1998 Human hydroxysteroid sulfotransferase SULT2B1: two enzymes encoded by a single chromosome 19 gene. Genomics 53 284-295. (https://doi. org/10.1006/geno.1998.5518)

Hobkirk R, Renaud R \& Raeside JI 1989 Partial characterization of steroid sulfohydrolase and steroid sulfotransferase activities in purified porcine Leydig cells. Journal of Steroid Biochemistry 32 387-392. (https://doi.org/10.1016/0022-4731(89)90211-2)

Hoffmann B, Rostalski A, Mutembei HM \& Goericke-Pesch S 2010 Testicular steroid hormone secretion in the boar and expression of testicular and epididymal steroid sulphatase and estrogen sulphotransferase activity. Experimental and Clinical Endocrinology and Diabetes 118 274-280.

Holmseth S, Zhou Y, Follin-Arbelet VV, Lehre KP, Bergles DE \& Danbolt NC 2012 Specificity controls for immunocytochemistry: the antigen preadsorption test can lead to inaccurate assessment of antibody specificity. Journal of Histochemistry and Cytochemistry $\mathbf{6 0}$ 174-187. (https://doi.org/10.1369/0022155411434828)

Hughes J \& Berger T 2015 Development of apical blebbing in the boar epididymis. PLoS ONE 10 e0126848. (https://doi.org/10.1371/journal. pone.0126848)

Javitt NB, Lee YC, Shimizu C, Fuda H \& Strott CA 2001 Cholesterol and hydroxycholesterol sulfotransferases: identification, distinction from dehydroepiandrosterone sulfotransferase, and differential tissue expression. Endocrinology 142 2978-2984. (https://doi.org/10.1210/ endo.142.7.8244)

Keber R, Rozman D \& Horvat S 2013 Sterols in spermatogenesis and sperm maturation. Journal of Lipid Research 54 20-33. (https://doi. org/10.1194/jlr.R032326)

Kohjitani A, Fuda H, Hanyu O \& Strott CA 2006 Cloning, characterization and tissue expression of rat SULT2B1a and SULT2B1b steroid/sterol sulfotransferase isoforms: divergence of the rat SULT2B1 gene structure from orthologous human and mouse genes. Gene 367 66-73. (https://doi.org/10.1016/j.gene.2005.09.009)

Mahony MC, Swanlund DJ, Billeter M, Roberts KP \& Pryor JL 1998 Regional distribution of 5alpha-reductase type 1 and type 2 mRNA along the human epididymis. Fertility and Sterility 69 1116-1121. (https://doi.org/10.1016/S0015-0282(98)00094-6)
Meloche CA \& Falany CN 2001 Expression and characterization of the human 3beta-hydroxysteroid sulfotransferases (SULT2B1a and SULT2B1b). Journal of Steroid Biochemistry and Molecular Biology 77 261-269. (https://doi.org/10.1016/S0960-0760(01)00064-4)

Moe M, Grindflek E \& Doran O 2007a Expression of 3betahydroxysteroid dehydrogenase, cytochrome P450-c17, and sulfotransferase $2 \mathrm{~B} 1$ proteins in liver and testis of pigs of two breeds: relationship with adipose tissue androstenone concentration. Journal of Animal Science $\mathbf{8 5}$ 2924-2931. (https://doi.org/10.2527/jas.20070283)

Moe M, Meuwissen T, Lien S, Bendixen C, Wang X, Conley LN, Berget I, Tajet H \& Grindflek E $2007 b$ Gene expression profiles in testis of pigs with extreme high and low levels of androstenone. BMC Genomics $\mathbf{8}$ 405. (https://doi.org/10.1186/1471-2164-8-405)

Moe M, Lien S, Bendixen C, Hedegaard J, Hornshøj H, Berget I, Meuwissen TH \& Grindflek E 2008 Gene expression profiles in liver of pigs with extreme high and low levels of androstenone. BMC Veterinary Research 4 29. (https://doi.org/10.1186/1746-6148-4-29)

Mueller JW, Gilligan LC, Idkowiak J, Arlt W \& Foster PA 2015 The regulation of steroid action by sulfation and desulfation. Endocrine Reviews 36 526-563. (https://doi.org/10.1210/er.2015-1036)

Normington K \& Russell DW 1992 Tissue distribution and kinetic characteristics of rat steroid 5 alpha-reductase isozymes. Evidence for distinct physiological functions. Journal of Biological Chemistry 267 19548-19554.

Orava M, Haour F, Leinonen P, Ruokonen A \& Vihko R 1985 Relationships between unconjugated and sulphated steroids in porcine primary Leydig cell culture. Journal of Steroid Biochemistry 22 507-512. (https://doi.org/10.1016/0022-4731(85)90170-0)

Pasqualini JR 2009 Estrogen sulfotransferases in breast and endometrial cancers. Annals of the New York Academy of Sciences 1155 88-98. (https://doi.org/10.1111/j.1749-6632.2009.04113.x)

Pujol A \& Bayard F 1978 5alpha-reductase and 3alpha-hydroxysteroid oxidoreductase enzyme activities in epididymis and their control by androgen and the rete testis fluid. Steroids 31 485-493. (https://doi. org/10.1016/0039-128X(78)90030-2)

Raeside JI \& Howells GA 1971 The isolation and identification of androstenediol sulfate from spermatic vein blood and testes of the boar. Canadian Journal of Biochemistry 49 80-84. (https://doi. org/10.1139/o71-012)

Raeside JI \& Renaud RL 1983 Estrogen and androgen production by purified Leydig cells of mature boars. Biology of Reproduction $\mathbf{2 8}$ 727-733. (https://doi.org/10.1095/biolreprod28.3.727)

Raeside JI, Renaud RL \& Marshall DE 1992 Identification of 5 alphaandrostane-3beta, 17 beta-diol and 3 beta-hydroxy-5 alpha-androstan17-one sulfates as quantitatively significant secretory products of porcine Leydig cells and their presence in testicular venous blood. Journal of Steroid Biochemistry and Molecular Biology 42 113-120. (https://doi.org/10.1016/0960-0760(92)90017-D)

Raeside JI, Christie HL, Renaud RL \& Sinclair PA 2006 The boar testis: the most versatile steroid producing organ known. Society of Reproduction and Fertility Supplement 62 85-97.

Rasmussen MK, Brunius C, Ekstrand B \& Zamaratskaia G 2012 Expression of hepatic 3 $\beta$-hydroxysteroid dehydrogenase and sulfotransferase 2A1 in entire and castrated male pigs. Molecular Biology Reports 39 7927-7932. (https://doi.org/10.1007/s11033-0121637-5)

Robaire B \& Henderson NA 2006 Actions of 5alpha-reductase inhibitors on the epididymis. Molecular and Cellular Endocrinology 250 190-195. (https://doi.org/10.1016/j.mce.2005.12.044)

Roberts KD 1987 Sterol sulfates in the epididymis; synthesis and possible function in the reproductive process. Journal of Steroid Biochemistry 27 337-341. (https://doi.org/10.1016/0022-4731(87)90325-6)

Robic A, Feve K, Riquet J \& Prunier A 2016 Transcript levels of genes implicated in steroidogenesis in the testes and fat tissue in relation 
to androstenone accumulation in fat of pubertal pigs. Domestic Animal Endocrinology 57 1-9. doi:10.1016/j.domaniend.2016.03.008.

Ruokonen A \& Vihko R 1974 Steroid metabolism in testis tissue: concentrations of unconjugated and sulfated neutral steroids in boar testis. Journal of Steroid Biochemistry 5 33-38. (https://doi. org/10.1016/0022-4731(74)90025-9)

Sakakibara Y, Yanagisawa K, Takami Y, Nakayama T, Suiko M \& Liu MC 1998 Molecular cloning, expression, and functional characterization of novel mouse sulfotransferases. Biochemical and Biophysical Research Communications 247 681-686. (https://doi.org/10.1006/ bbrc.1998.8872)

Schuler G, Dezhkam Y, Bingsohn L, Hoffmann B, Failing K, Galuska CE, Hartmann MF, Sánchez-Guijo A \& Wudy SA 2014 Free and sulfated steroids secretion in postpubertal boars (Sus scrofa domestica). Reproduction 148 303-314. (https://doi.org/10.1530/REP-14-0193)

Schuler G, Sánchez-Guijo A, Hartmann MF \& Wudy SA 2018a Simultaneous profiles of sulfonated androgens, sulfonated estrogens and sulfonated progestogens in postpubertal boars (sus scrofa domestica) measured by LC-MS/MS. Journal of Steroid Biochemistry and Molecular Biology 179 55-63. (https://doi.org/10.1016/j. jsbmb.2017.10.006)

Schuler G, Dezhkam Y, Tenbusch L, Klymiuk MC, Zimmer B \& Hoffmann B 2018b Formation and hydrolysis of sulfonated estrogens in the porcine testis and epididymis. Journal of Molecular Endocrinology 61 M15-M27. (https://doi.org/10.1530/JME-17-0245)

Schwarzenberger F, Toole GS, Christie HL \& Raeside JI 1993 Plasma levels of several androgens and estrogens from birth to puberty in male domestic pigs, Acta Endocrinologica 128 173-177.

Setchell BP, Laurie MS, Flint AP \& Heap RB 1983 Transport of free and conjugated steroids from the boar testis in lymph, venous blood and rete testis fluid. Journal of Endocrinology 96 127-136. (https://doi. org/10.1677/joe.0.0960127)

Shea HC, Head DD, Setchell KD \& Russell DW 2007 Analysis of HSD3B7 knockout mice reveals that a 3alpha-hydroxyl stereochemistry is required for bile acid function. PNAS 104 11526-11533. (https://doi. org/10.1073/pnas.0705089104)

Shimizu C, Fuda H, Yanai H \& Strott CA 2003 Conservation of the hydroxysteroid sulfotransferase SULT2B1 gene structure in the mouse: pre- and postnatal expression, kinetic analysis of isoforms, and comparison with prototypical SULT2A1, Endocrinology 144 1186-1193. (https://doi.org/10.1210/en.2002-221011)

Sinclair PA, Squires EJ, Raeside JI \& Renaud R 2005 Synthesis of free and sulphoconjugated 16-androstene steroids by the Leydig cells of the mature domestic boar. Journal of Steroid Biochemistry and Molecular Biology 96 217-228. (https://doi.org/10.1016/j.jsbmb.2005.02.017)

Sinclair PA, Gilmore WJ, Lin Z, Lou Y \& Squires EJ 2006 Molecular cloning and regulation of porcine SULT2A1: relationship between SULT2A1 expression and sulfoconjugation of androstenone. Journal of Molecular Endocrinology 36 301-311. (https://doi.org/10.1677/ jme.1.01847)

Strott CA 2002 Sulfonation and molecular action. Endocrine Reviews 23 703-732. (https://doi.org/10.1210/er.2001-0040)

Wiszniewska B 2001 Steroidogenic characteristics of in vitro cultured epididymal epithelial cells of the rat. Reproductive Biology 1 60-66.

Wiszniewska B 2002 Primary culture of the rat epididymal epithelial cells as a source of oestrogen. Andrologia 34 180-187. (https://doi. org/10.1046/j.1439-0272.2002.00495.x)

Zduńczyk S, Janowski T, Raś A \& Barański W 2012 Activity of steroid sulphatase and estrogen sulphotransferase in the boar epididymis during the postpubertal period. Reproductive Biology 12 374-378.

Received in final form 16 March 2018

Accepted 27 March 2018

Accepted Preprint published online 27 March 2018 (c) 2018 Society for Endocrinology Published by Bioscientifica Ltd. Printed in Great Britain 